\title{
The economic impact of preschool asthma and wheeze
}

\author{
C.A. Stevens*, D. Turner", C.E. Kuehni", J.M. Couriel ${ }^{+}$, M. Silverman*
}

The economic impact of preschool asthma and wheeze. C.A. Stevens, D. Turner, C.E. Kuehni, J.M. Couriel, M. Silverman. C) ERS Journals Ltd 2003.

ABSTRACT: The aim of the present study was to determine the economic impact in the UK of wheezing disorders in preschool children.

Health, societal and family-borne costs were calculated for a sample of 94 preschool children who attended hospital with a primary diagnosis of wheeze or asthma during 1998/1999. Sample costs were calculated using data from a structured interview schedule and from symptom diaries completed by trial parents, patients' general practice and hospital records, and hospital finance data. Health costs for 1-5-yr-olds in the UK were calculated using data from a postal population survey in the same region.

It is estimated that 1-5-yr-old children with wheeze in the UK cost the health service a total of 53 million UK pounds (GBP). The greatest expenditure, 34 million GBP, was for primary care, representing $65.2 \%$ of total healthcare costs. Prescription costs represented $20.4 \%$ (11 million GBP) of total healthcare costs.

Caring for preschool children with wheeze in the UK cost the health service $0.15 \%$ of its total budget in 1998/1999. The total costs to society of caring for the $0.88 \%$ of preschool children who attended hospital for asthma or wheeze in a year represented a further $\mathbf{2 . 6}$ million UK pounds. Primary prevention strategies at the population level promise more cost savings than any attempt at decreasing hospitalisations in those more severely ill.

Eur Respir J 2003; 21: 1000-1006.
*Leicester Children's Asthma Centre and ${ }^{\#}$ Dept of Epidemiology and Public Health, University of Leicester, Leicester, and ${ }^{+}$Respiratory Unit, Royal Liverpool Children's Hospital, Liverpool, UK. 'Dept of Social and Preventive Medicine and University Children's Hospital, University of Bern, Bern, Switzerland.

Correspondence: C.A. Stevens, Division of Primary Care, 13th Floor, Tower Building, University of Nottingham, Nottingham, NG7 2RD, UK.

Fax: 441158466904

E-mail: Caroline.Mulvaney@nottingham.ac.uk

Keywords: Asthma, health, preschool, society and family costs, wheeze

Received: July 12002

Accepted after revision: January 62003

This study was funded by the National Health Service (NHS) Executive Mother and Child Health Programme, London, UK (MCH 1615). The population survey was funded by the Swiss National Science foundation, Bern, Switzerland (SNF No. 823B - 046481) and the Trent NHS Executive, Sheffield, UK (RBF No. $98 \times X 3)$.
The economics of healthcare are becoming increasingly important. There is growing realisation that health budgets cannot meet all possible demands on them and that choices have to be made as to the best use of resources. Although estimation of the costs of providing care for patients with a particular disease is imprecise, it provides insight into the distribution of costs and can help to identify targets for potential cost savings through adoption of cost-effective healthcare technologies.

As a chronic condition requiring long-term care, asthma has a large financial impact on the healthcare system and also on patients' families and society in general. Worsening symptoms in a child with asthma or wheeze may require a visit to the general practitioner (GP) or hospital, incurring both direct and indirect costs and taking time away from waged or nonwaged activities.

Estimates of both the direct and indirect costs of providing care to patients of all ages with asthma have been published for several countries, including the UK [1-9]. Cost estimates specifically for children with wheeze or asthma have been performed in a few countries [10-13]. However, no publications report on the wider economic impact on families and society of asthma and wheeze in the preschool population of the UK.

In the context of a randomised controlled trial (RCT) [14], the costs to the family, the health service and wider society of caring for a preschool child recently admitted to hospital with a primary diagnosis of asthma or wheeze in Leicestershire,
UK, were evaluated. These data were supplemented by a postal population survey of respiratory health in under-fives performed at the same time in Leicestershire [15]. In the present study, the economic impact of asthma in the UK for this group of under-fives is described. All costs are based on 1998/1999 figures.

\section{Study design and methods}

\section{Study design}

During the course of a RCT designed to examine the impact on morbidity of providing an educational intervention and self-management plan to the parents of children aged 18 months -5 yrs who had recently attended hospital with a primary diagnosis of asthma or wheeze [14], data were collected on healthcare resource use and familial, healthcare and employment costs. Between February 1998-March 1999, 200 children were recruited to the trial from either a children's ward or the accident and emergency department of Leicester Royal Infirmary (Leicester, UK) or Booth Hall Children's Hospital (Manchester, UK). Two-thirds (67\%, 134 of 200) of the sample were males and 79.5\% (159 of 200) and 14\% (28 of 200) were of Caucasian and South Asian (Bangladesh, Bhutan, India, Maldives, Nepal, Pakistan and Sri Lanka) origin, respectively. Of these 200 children, 110 resided in Leicestershire, for which recent population survey data are 
available [15], enabling estimation of the costs of wheeze in preschool children. Of this subset of 110 children, complete data on healthcare resource use and familial, healthcare and employment costs were available for 94 families and form the basis of the present report. For the 90 children in the study who attended the trial centre in Manchester, similar population survey data were not available and so they were discounted from this cost of illness evaluation.

The methods used to collect the cost data within the RCT, use of the population survey data and subsequent cost calculations are described below. The reader is referred to a previous publication for a detailed description of the RCT [14].

\section{Collection of cost data}

At the end of the trial period, the study team completed a structured interview schedule with parents to assess familyborne costs and the value of waged and nonwaged time lost as result of the family caring for their preschool child with wheeze or asthma during the previous year. The interview schedule explored the costs incurred by parents when their child was unwell with asthma according to five possible scenarios: caring for the child at home; attending the GP's surgery; attending hospital for an outpatient consultation; attending the accident and emergency department (A\&E); and being cared for as an inpatient. Cost data were collected only for those scenarios encountered by each family during the previous year.

\section{Family-borne costs}

For each of the five scenarios encountered by the family, family-borne costs were calculated according to three categories: 1) cost of providing a carer to mind either the unwell child, when the child required care at home and the usual parent/carer continued to work, or other dependants, when the parent/carer accompanied the child to a consultation; 2) cost of travel calculated for either the cost of fares on public transport or, in the case of car travel, the distance of the family home from the GP's surgery or hospital with cost of car travel set at $0.3956 \mathrm{UK}$ pounds $(\mathrm{GBP}) \cdot \mathrm{mile}^{-1}[16]$, and, if the child was admitted to hospital as an inpatient, how frequently the journey to hospital was made each day; and 4) out-of-pocket expenses such as excess costs of drinks, meals, magazines, newspapers and telephone calls. For each scenario, parents were asked to recall the costs typically incurred. For inpatient stays, parents were asked to recall their costs for a typical 24-h period.

Family-borne costs incurred while caring for the unwell child at home were based only on the costs of providing a childminder, if required. Although caring for an unwell child at home may incur other family-borne costs such as extra heating, particularly during the winter months, these are difficult to determine and quantify and were omitted from the cost calculations.

Family-borne costs incurred while taking the child to the surgery were based on travelling and childminding costs alone as it was assumed that there would be few, if any, further outof-pocket expenses, such as drinks or food, during such a relatively short time period.

For the four scenarios entailing either a GP consultation or attendance at hospital for which it was considered possible that two caregivers would adopt major care roles, costs for the primary caregiver, who was identified as spending most time with the child, and the secondary caregiver, who spent less time with the child, were determined separately.

Data were also collected on regular monthly purchases made by parents of items that they believed would relieve their child's symptoms. The purchase costs of occasional expensive items, such as vacuum cleaners and hypoallergenic bedlinen, were not included.

Data from the RCT [14] provided evidence on the number of surgery consultations and attendances at hospital made by each child. Symptom diaries provided data on the number of occasions when the unwell child was cared for at home. Trial families were asked to complete a 4-week symptom diary on three occasions during the 12-month trial period. Parents were asked to indicate when their child was unwell at home with asthma. However, the number of days when the child was unwell is an underestimate as not all of the 94 trial families completed symptom diaries. Of a possible 282 symptom diaries (94 families completing symptom diaries on three occasions), only $137(48.5 \%)$ were successfully completed and returned.

Using these data on family-borne costs for each care scenario and the number of such events from the RCT data [14], it was possible to calculate family-borne costs for each family over a 12-month period.

\section{Costs of time lost from waged and nonwaged employment}

Time spent caring for a child who is unwell represents a loss of time that could have been spent on other activities including waged employment or nonwaged pursuits. In order to estimate the costs of time lost from waged and nonwaged employment, parents were asked, for each scenario encountered, who would usually care for the child under such circumstances and whether this would require them taking time off from paid employment. Parents were then asked to estimate the typical duration of each event, based on experience, including travelling time to and from the surgery or hospital. As for family-borne costs, for each of the four scenarios entailing either a GP consultation or attendance at hospital, parents were asked about the time costs incurred by both the principal and secondary caregiver.

When the child was unwell at home, the costs of lost nonwaged employment were assumed to be zero since a disease such as childhood asthma is unlikely to require intensive input from carers except for short periods, e.g. during drug administration. Likewise, estimates of lost waged time were based on those of just one parent as it was considered likely that the child would require the care of only one caregiver at a time. Time lost from waged employment when caring for the child at home was assessed using symptom diary data, which indicated when the unwell child was cared for at home.

The value of time lost from paid employment was estimated using mean wages for male and female workers in the East Midlands, the region in which Leicestershire is situated, for April 1999 [17, 18]. This method results in a mean weekly gross wage of $398.30 \mathrm{GBP}$ for $42.1 \mathrm{~h}\left(9.46 \mathrm{GBP} \cdot \mathrm{h}^{-1}\right)$ for a male and $286.70 \mathrm{GBP}$ for $37.8 \mathrm{~h}\left(7.58 \mathrm{GBP} \cdot \mathrm{h}^{-1}\right)$ for a female. Costs of nonwaged time can be represented as the opportunity costs of tasks that would otherwise have been carried out, e.g. household chores $[19,20]$. This was estimated using the mean wage for a local authority home-care worker, i.e. 5.11 GBP $\cdot \mathrm{h}^{-1}[21]$.

Using these mean wages, parental estimates of time spent for each scenario and RCT data [14] from symptom diaries and the number of GP consultations and attendances at 
hospital, it was possible to calculate the value of lost waged and nonwaged employment for each family over a 12-month period.

It was assumed that family-borne waged and nonwaged costs incurred during visits to the surgery would be the same whether the consultation was with the GP or practice nurse and thus costs were calculated using the sum of all surgery consultations.

Similarly, costs were calculated only for those consultations requiring the child to attend the surgery and not for GP consultations at home.

\section{Health-service costs}

Health-service costs refer to the direct medical costs of providing primary and secondary care and medication. These costs were obtained from various sources and were used to calculate the total health costs of the 94 trial families.

A primary care consultation with a GP was costed at 16 GBP for a surgery consultation and 49 GBP for a home visit [21]. A consultation with the practice nurse at the surgery was costed at 9.14 GBP [21].

Secondary care costs were obtained from the finance department of Leicester Royal Infirmary. An outpatient appointment cost $113 \mathrm{GBP}$ for a new patient and $56 \mathrm{GBP}$ for an existing patient. As it was not possible to determine whether the first appointment attended during the 12-month trial period was as a new or existing patient, a conservative estimate was made, assuming that all outpatient appointments were for existing patients. An emergency visit to A\&E costs 35 GBP. The cost of an inpatient stay was estimated using Healthcare Resource Group prices, which are based on several factors including length of stay and primary diagnosis [22].

The cost of drugs prescribed to the children was taken from a published source [23]. The costs of inpatient and discharge drugs prescribed following any attendance at hospital during the 12-month trial period were not included in the calculations as this would have required examination of the hospital notes of all 94 children.

\section{Use of healthcare resources}

As part of the RCT, the numbers of GP and practice-nurse consultations, including the number of home visits, made during the 12-month trial period were obtained from the patient's GP records. From these records, prescription data, including the type of medication and the dosage for each child in the 12-month trial period, were also obtained. The number of visits made to the hospital for outpatient appointments or to A\&E and the number of days spent as an inpatient were determined from case notes and hospital records.

Using the health-service costs and data on healthcare resources used by the 94 families, the total and mean costs of providing healthcare to all the families over a 12-month period were calculated.

\section{Use of population survey data}

Data from the RCT [14], a population survey [15] and a personal communication (C. Kuehni, Dept of Social and Preventive Medicine, University of Bern, Bern, Switzerland,
September 20, 2001) were used to estimate morbidity due to asthma and wheeze in the preschool population of Leicestershire.

During the 13 months in which recruitment to the RCT [14] took place, a total of 383 different children aged 18 months5 yrs were either admitted to Leicester Royal Infirmary (the only secondary care centre in the county) as an inpatient or attended $A \& E$ as a first attendance. Therefore, it can be estimated that during a 12-month period, 354 different preschool children aged 18 months to 5 yrs within Leicestershire attended hospital with a primary diagnosis of asthma or wheeze. Assuming that hospital admission rates for those aged 12-18 months are the same as for those aged 18 months$5 \mathrm{yrs}$, it is estimated that 404 different preschool children aged 1-5 yrs attended hospital in Leicestershire with a primary diagnosis of asthma or wheeze, representing $0.88 \%$ (404 of $46,160)$ of the total Leicestershire population aged $1-5$ yrs (A. Davies, Leicester City West Primary Care Trust, Leicester, UK, personal communication dated April 10, 2000).

Data collected via a postal questionnaire sent to the parents of >3,410 Leicestershire children in 1998 (C. Kuehni, personal communication dated September 20, 2001) showed that $24.6 \%(827$ of 3,358$)$ of preschool children aged $1-5 \mathrm{yrs}$ had reported wheeze or asthma during the previous 12 months [15]. Of those children reporting wheeze, $93.5 \%$ (773 of 827) had consulted their GP with symptoms [15]; this represents $23.0 \%(773$ of 3,358$)$ of the total preschool population aged 1-5 yrs. Of those children who consulted their GP, the greatest number of children, $43.2 \%$ (331 of 766), consulted their GP two or three times during the year, with $58.2 \%$ (446 of 766) receiving treatment and 41.8\% (320 of 766) not receiving treatment (seven nonrespondents).

\section{Estimates of population morbidity in the $U K$}

Estimates of population morbidity in Leicestershire were used to estimate the population morbidity of the UK preschool population.

In $1998,6.2 \%$ (3.67 million) of the UK population of 59.2 million were aged $<5$ yrs [17]. Accordingly, it is estimated that 2.94 million $(0.8 \times 3.67$ million $)$ were aged $1-5$ yrs. If, in 1998 , $24.6 \%$ of these wheezed during a 12-month period, estimates suggest that 0.72 million children in the UK aged 1-5 yrs wheezed. Furthermore, if $0.88 \%$ of preschool children attend hospital in $1 \mathrm{yr}$ due to asthma or wheeze, then, potentially, in 1998 in the UK, 25,850 children aged 1-5 yrs attended hospital for wheeze or asthma.

The above figures are used in the calculations of preschool asthma or wheeze-related health and societal costs. The estimates of population morbidity presented here compare favourably with other data sources that report that $\sim 22 \%$ of preschool children reported wheeze in the previous 12 months [24] albeit higher than the reported wheeze of older children [8].

\section{Cost calculations}

Estimates of health-service costs, family-borne costs, and the value of waged and nonwaged time for the $0.88 \%$ of the UK preschool population admitted to secondary care were based on mean healthcare costs from the present sample. This assumes that healthcare-resource use in this sample approximates to that of all families in the UK with a child hospitalised due to wheezing.

To calculate healthcare costs for those children who attended only primary care for wheeze, the present sample healthcare-cost estimates were not thought to be adequately 
representative. The mean number of GP consultations for wheeze or cough in the sample children was 4.8 [14]. Data from the population survey showed that, of the 3,410 respondents, $1,283(37.6 \%)$ were South Asians, who were found to consult their GP more frequently than Caucasians (e.g. mean number of GP consultations for wheeze or cough in children with current wheeze was 3.0 in Caucasians and 3.6 in South Asians) (C. Kuehni, personal communication dated September 20, 2001). However, in the UK as a whole, South Asians represent $\sim 2.5 \%$ of the population [25]. Therefore, to calculate healthcare costs for those attending only primary care, estimates of the number of GP visits made by Caucasians in the population survey [15], being more representative of the UK population, were combined with the unit cost of a GP visit [21]. All visits to the surgery are costed according to a consultation with the GP as no data are available from the population survey on consultations with the practice nurse. No information was available regarding prescription costs for inhaler treatment for those attending only primary care and, therefore, mean prescription costs from the sample of 94 families were used.

The distribution of the National Health Service (NHS) cost data was skewed with relatively few children contributing excessively to the total costs. However, service providers are concerned with the mean cost of an event as this allows direct calculation of costs for samples of different size. Therefore, costs are presented as mean \pm SD and median $(95 \%$ confidence interval).

\section{Results}

\section{Data from the 94 trial children}

Data showed that they had a mean of 5.4 consultations with their GP or practice nurse during the 12-month followup period. There were $52(55.3 \%)$ reported episodes managed at home, $11(11.8 \%)$ attendances at $A \& E$ due to asthma or wheeze and $29(30.9 \%)$ were admitted to hospital (for a total of 61days) (table 1).

Costs of inpatient stays represented $56.8 \%$ of total healthcare costs (fig. 1).

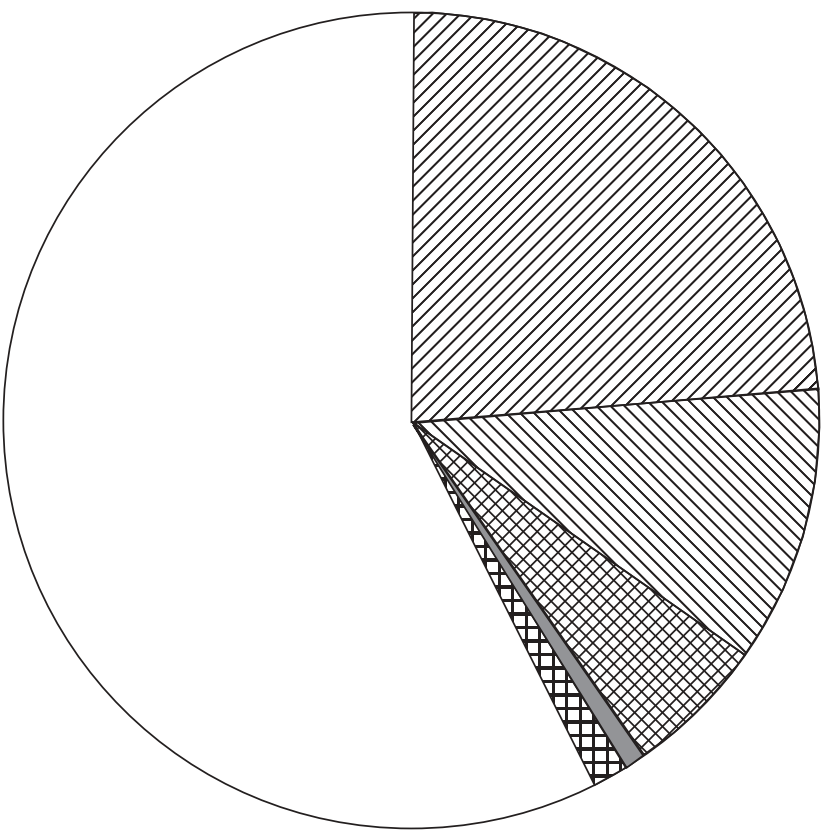

Fig. 1. - Distribution of healthcare costs for preschool children in the UK during a 12-month period following attendance at hospital for wheeze or asthma ( $\square$ : inpatient; $\mathbb{Z}$ : general practitioner; $\mathbb{Q}$ : outpatient; : prescription; : accident and emergency department; 曲: practice nurse).

Family-borne costs and healthcare costs represent 5.6 and $76.3 \%$, respectively, of total costs (fig. 2).

The mean family-borne costs of looking after a preschool child following attendance or admission to hospital was $31.86 \pm 43.27 \mathrm{GBP} \cdot \mathrm{yr}^{-1}$, of which almost one-half was due to the cost of regular purchases such as cough medicines (table 1).

When the families cared for their unwell child at home, no direct costs were documented; although three families had to arrange a childminder for the child while they went to work, none had to pay for this help. The mean daily cost to families when their child was in hospital was 10.08 $\pm 39.30 \mathrm{GBP}$ (table 1).

Table 1.-Annual family-borne, nonwaged and waged time lost, and health-service costs for 94 trial families

\begin{tabular}{|c|c|c|c|c|c|}
\hline & $\begin{array}{l}\text { Events } \mathrm{n} \\
\text { Total mean }\end{array}$ & $\begin{array}{l}\text { Family-borne } \\
\text { GBP }\end{array}$ & $\begin{array}{c}\text { Nonwaged time } \\
\text { GBP }\end{array}$ & $\begin{array}{l}\text { Waged time } \\
\text { GBP }\end{array}$ & $\begin{array}{l}\text { Health service } \\
\text { GBP }\end{array}$ \\
\hline Illness at home & $52 \pm 0.55$ & & & $9.93^{\#}$ & \\
\hline GP consultations & $452 \pm 4.81$ & $2.81 \pm 6.13^{\top}$ & $25.08 \pm 67.18^{\bullet}$ & $6.61 \pm 16.95^{\circ}$ & $\begin{array}{c}103.00 \pm 81.26 \\
80.00(0-283.8)\end{array}$ \\
\hline Practice nurse consultations & $53 \pm 0.56$ & $0.95(0-20.59)$ & $10.43(0-110.82)$ & $0(0-59.41)$ & $\begin{array}{l}5.15 \pm 16.77 \\
0(0-27.42)\end{array}$ \\
\hline Prescription items & $605 \pm 6.44$ & & & & $\begin{array}{c}26.62 \pm 25.79 \\
19.26(0-97.21)\end{array}$ \\
\hline A\&E attendances & $11 \pm 0.12$ & $\begin{array}{r}0.36 \pm 1.71 \\
0(0-6.64)\end{array}$ & $\begin{array}{r}2.09 \pm 13.62 \\
0(0-21.53)\end{array}$ & $\begin{array}{r}0.70 \pm 4.42 \\
0(0-3.19)\end{array}$ & $\begin{array}{c}4.10 \pm 12.42 \\
0(0-35.00)\end{array}$ \\
\hline Inpatient days & $61 \pm 0.65$ & $\begin{array}{r}10.08 \pm 39.30 \\
0(0-63.00)\end{array}$ & $\begin{array}{l}16.20 \pm 47.87 \\
0(0-160.33)\end{array}$ & $\begin{array}{r}32.11 \pm 185.75 \\
0(0-242.56)\end{array}$ & $\begin{array}{l}243.17 \pm 451.93 \\
0(0-1604.00)\end{array}$ \\
\hline Outpatient attendances & $78 \pm 0.83$ & $\begin{array}{l}3.68 \pm 7.88 \\
0(0-22.34)\end{array}$ & $\begin{array}{l}3.19 \pm 9.37 \\
0(0-37.56)\end{array}$ & $\begin{array}{l}5.67 \pm 15.91 \\
0(0-53.09)\end{array}$ & $\begin{array}{l}46.47 \pm 66.02 \\
\quad 0(0-224.00)\end{array}$ \\
\hline Regular family expenditure & & $\begin{array}{l}14.94 \pm 43.27 \\
0(0-168.3)\end{array}$ & & & \\
\hline Total & & $\begin{array}{l}31.86 \pm 43.27 \\
6.46(0-219.37)\end{array}$ & $\begin{array}{c}\text { 46.57 } \pm 92.30 \\
17.89(0-201.21)\end{array}$ & $\begin{array}{l}55.02 \pm 218.77 \\
0(0-356.86)\end{array}$ & $\begin{array}{c}428.51 \pm 510.39 ; \\
178.33(34.07-1781.89)\end{array}$ \\
\hline
\end{tabular}

Data are presented as mean \pm SD and median (95\% confidence interval). GBP: UK pounds; GP: general practitioner; A\&E: accident and emergency department. ${ }^{\#}$ : single event; ${ }^{\circ}$ : general practitioner and practice nurse consultations costed together. 


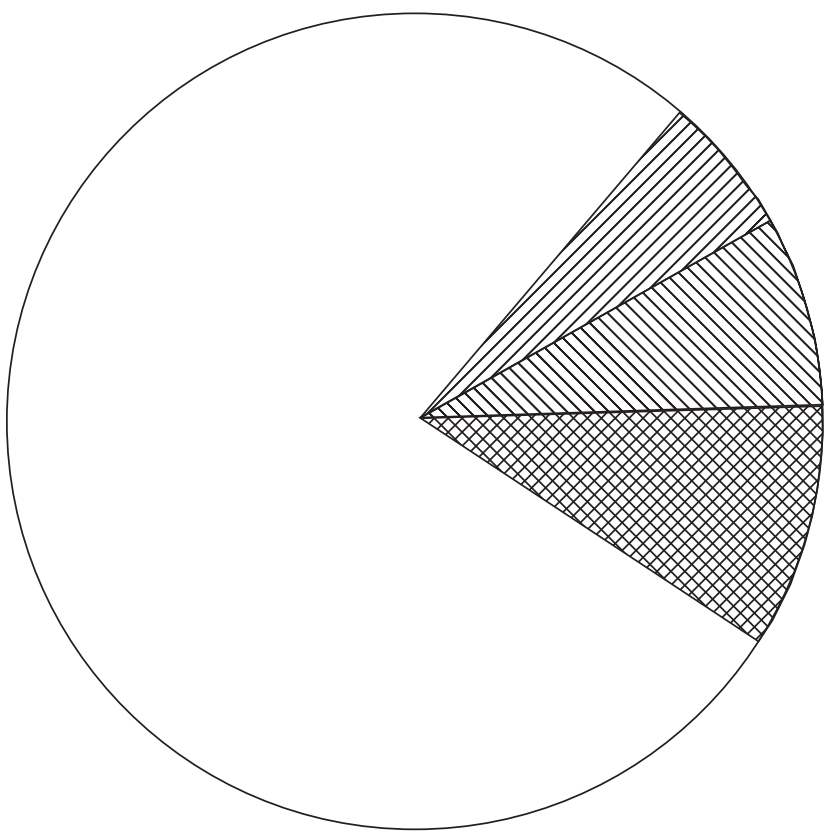

Fig. 2.-Distribution of all costs incurred caring for preschool children in the UK during a 12-month period following attendance at hospital for wheeze or asthma ( $\square$ : healthcare; $\mathbb{Z}$ : family-borne; $\mathbb{\mathbb { V }}$ : unwaged time lost; $\mathbf{0}$ : waged time lost).

The costs of time lost from waged and nonwaged employment were similar (table 2), representing $18 \%$ of overall costs (fig. 2).
As might be expected for the trial population, inpatient costs constitute the greatest proportion of health-service costs $(56.8 \%)$, whereas drug costs represent $6.2 \%$ of total healthcare costs (fig. 1).

\section{In the UK as a whole}

It is estimated that, in the 12 months following attendance at hospital for wheeze or asthma, children aged 1-5 yrs have 124,400 GP consultations, costing the health service 2.66 million GBP and make 21,500 outpatient department visits costing 1.20 million GBP (table 2). These children spend 16,800 bed-days in hospital costing 6.29 million GBP and make 3,100 emergency visits to A\&E costing 0.11 million GBP (table 2). The total healthcare costs for this group of children are estimated at 11.08 million GBP.

It is estimated that those attending primary care only and receiving treatment make 1.40 million visits to the GP costing 22.36 million GBP, whereas those not receiving treatment have 0.58 million consultations with the GP costing 9.23 million GBP (table 3).

In the UK as a whole, families spent an estimated 0.82 million GBP providing care to a child admitted to hospital with wheeze within the last 12 months (table 2). The cost to society as a whole for this group of children amounted to 14.53 million GBP.

Prescription costs amount to 10.8 million GBP (table 3). Consequently, the total healthcare costs for all 1-5-yr-olds in the UK reporting wheeze are estimated to be 52.75 million GBP (1998/1999 figures).

Table 2. - Estimates of family-borne, nonwaged and waged time lost and healthcare costs for all 25,855 children in the UK aged $1-5$ yrs who received secondary care for wheeze or asthma during a 12-month period in 1998/1999

$\begin{array}{lcccc}\begin{array}{c}\text { Family-borne } \\ \text { million GBP }\end{array} & \begin{array}{c}\text { Nonwaged time } \\ \text { million GBP }\end{array} & \text { Waged time } & \text { Healthcare } & \text { Total } \\ \text { million GBP } & \text { million GBP } & \text { million GBP }\end{array}$

Illness at home

GP consultations

Practice nurse consultations

Prescription items

A\&E attendances

Inpatient days

Outpatient attendances

Regular family expenditure

Total

Proportion of overall costs \% million GBP

million GBP

$\begin{array}{ll}0.26 & 2.66 \\ & \\ 0.17 & 0.13 \\ & 0.69 \\ 0.02 & 0.11 \\ 0.83 & 6.29 \\ 0.15 & 1.20 \\ & \\ 1.43 & 11.08 \\ 9.8 & 76.3\end{array}$

8.3
0.69

0.11

1.20

76.3

GBP: UK pounds; GP: general practitioner; A\&E: accident and emergency department.

Table 3. - Estimates of total annual healthcare costs for children in the UK aged 1-5 yrs with wheeze or asthma in 1998/1999 according to care received ${ }^{\#}$

$\begin{array}{cccc}\text { Primary and } & \text { Primary plus } & \text { Primary alone } & \text { Total } \\ \text { secondary } & \text { treatment } & \text { million GBP } & \text { million GBP } \\ \text { million GBP } & \text { million GBP } & & \end{array}$

\begin{tabular}{|c|c|c|c|c|}
\hline Children $n$ & 25855 & 378555 & 271659 & \\
\hline GP consultations & 2.66 & 22.36 & 9.23 & \\
\hline Practice nurse consultations & 0.13 & & & \\
\hline Prescription items & 0.69 & 10.08 & & \\
\hline A\&E attendances & 0.11 & & & \\
\hline In-patient days & 6.29 & & & \\
\hline Outpatient department attendances & 1.20 & & & \\
\hline Total & 11.08 & 32.44 & 9.23 & 52.75 \\
\hline
\end{tabular}

GBP: UK pounds; GP: general practitioner; A\&E: accident and emergency department. ${ }^{\#}$ : 47,304 received neither primary nor secondary care. 


\section{Discussion}

The overall cost to the family, health service and society associated with caring for children aged 1-5 yrs in the UK in the 12 months following attendance at hospital for wheeze or asthma was 14.53 million GBP, of which 11.08 million GBP was spent on health-service costs. Although inpatient stays incur the greatest direct costs to families and the greatest time costs to employers, visits to the GP incur the greatest nonwaged time costs. For all children aged $1-5$ yrs who attended either primary or secondary care with wheeze $(\sim 23 \%$ of the population at risk), the NHS costs totalled 52.75 million GBP, representing $0.15 \%$ of total NHS expenditure in 1998/ 1999 [26].

Comparisons of the family costs of caring for a child with asthma obtained in the present study with those in some previous studies [10-13] are difficult due to problems of currency conversion and inflation. A previous evaluation of healthcare costs for all paediatric asthma estimated total costs to be 107 million GBP in 1990 [9]. Allowing for inflation and the fact that most admissions to hospital and consultations with a GP for paediatric wheeze and asthma are in the preschool population, the present estimates are reasonable. In support of these findings, although the distribution of costs differed from that found in the present study, UNGAR and COYTE [13] found annual societal costs for asthma to be $23.5 \%$ higher in children aged $<4$ yrs than in those aged 4-14 yrs.

In the present study, primary care costs of 34.4 million GBP account for the greatest proportion of healthcare costs. They represent $65.2 \%$ of all healthcare costs, which is in contrast to cost evaluations performed in other countries, in which inpatient stays represent the greatest proportion of healthcare costs [4, 13]. Furthermore, previous studies $[2,9,13]$ have found medication costs to represent a greater proportion of costs than in the present study. This may be due to the fact that, commonly, preschool children suffering from viral-induced wheeze require little, if any, medication between episodes.

Several issues arise from the present methods of cost calculation. First, data on family costs and loss of time from waged and nonwaged employment were collected retrospectively at the end of the 12-month study period. Therefore, recall of events is one factor that may affect the results. Ideally, data would have been collected on each individual event that occurred during the 12-month trial period. Secondly, as previously stated, there were no nonwaged time costs recorded for caring for a child at home, all outpatient appointments were costed on the basis of being follow-up appointments rather than new consultations and costs of discharge drugs prescribed following attendance or admission at hospital during the 12-month trial period were not included in the cost calculations. These factors would lead to underestimation of the true costs. Thirdly, intangible costs to the family, such as worry and inconvenience or the costs associated with mortality (reasonably assumed to be negligible), were not considered in this analysis. Fourthly, although the index children had all attended hospital at some time for wheeze or asthma, 93\% [14] were on steps 1 or 2 of the British Thoracic Society guidelines [27], indicating "mild asthma". Finally, these data were collected as part of an RCT of guided self-management for preschool children with asthma or wheeze. However, since the intervention did not result in any significant difference in outcome between the control and intervention groups, it was possible to combine the costs of children from both in order to estimate total costs.

The validity of extrapolating data from only 94 families to the county or country depends on the degree to which they can be thought to represent preschool wheeze or asthma. The 94 trial children were recruited from 383 similar families who attended the only secondary care centre for children in Leicestershire over a period of 13 months [14]. Both the RCT and survey participants reside in Leicestershire and thus were recruited from comparable groups. Leicestershire is a county encompassing varied geographical areas including both innercity and rural areas. Previous research has shown that the geographical variation in asthma symptoms in schoolchildren within the UK is small [28].

The costs presented in the current article are based on a specific group of preschool children who attended hospital with wheeze or asthma requiring attendance at hospital at least once during a 12-month period in 1998/1999. The estimates of the overall costs of wheeze and asthma for the whole UK 1-5-yr-old population are clearly uncertain but provide a first and conservative estimate. At 53 million GBP, this represents $0.15 \%$ of total NHS expenditure. The greatest costs are for consultations in primary care and prescriptions. These should be the targets of future research endeavour.

In the long term, research into wheezing diseases in preschool children may lead to preventative programmes aimed at reducing their overall incidence, more effective therapies to reduce morbidity, and advice designed specifically for the families of the very young to reduce consultation rates. Although hospital costs account for most of the costs of the trial sample, the greatest proportion of costs for the whole of the UK is due to general practitioner consultations for children with relatively mild wheeze. Therefore, the introduction of primary prevention strategies at the population level promises much larger potential cost savings than any attempt at focusing on reducing hospitalisation in those more severely ill.

\begin{abstract}
Acknowledgements. The authors are indebted to all those families who participated in the present study. M. Partridge helped to prepare the initial research proposal under the auspices of the UK National Asthma Campaign, London, UK.
\end{abstract}

\section{References}

1. Szucs TD, Anderhub H, Rutishauser M. The economic burden of asthma: direct and indirect costs in Switzerland. Eur Respir J 1999; 13: 281-286.

2. Krahn MD, Berka C, Langlois P, Detsky AS. Direct and indirect costs of asthma in Canada, 1990. Can Med Assoc J 1996; 154: 821-831.

3. Weiss KB, Sullivan SD, Lyttle CS. Trends in the cost of illness for asthma in the United States, 1985-1994. J Allergy Clin Immunol 2000; 106: 493-499.

4. Chew FT, Goh DY, Lee BW. The economic cost of asthma in Singapore. Aust N Z J Med 1999; 29: 228-233.

5. Awadh BN, Grunfeld A, Fitzgerald JM. Health care costs associated with acute asthma: a prospective economic analysis. Can Respir J 1999; 6: 521-525.

6. Smith DH, Malone DC, Lawson KA, Okamoto LJ, Battista C, Saunders WB. A national estimate of the economic costs of asthma. Am J Respir Crit Care Med 1997; 156: 787-793.

7. Teeling-Smith G. Asthma. London, Office of Economics, 1990; p. 27.

8. Clark TJH. The costs of asthma. In: Action Asthma: the Occurrence and Cost of Asthma. Worthing, Cambridge Medical Publications, 1990; pp. 20ff.

9. Lenney W, Wells NEJ, O'Neill BA. The burden of paediatric asthma. Eur Respir Rev 1994; 4: 18, 49-62.

10. Toelle BG, Peat JK, Mellis CM, Woolcock AJ. The cost of 
childhood asthma to Australian families. Pediatr Pulmonol 1995; 19: 330-335.

11. Marion RJ, Gergen PJ, Hodgson TA. Direct and indirect costs associated with the management of childhood asthma. Ann Allergy 1985; 54: 31-34.

12. Lozano P, Sullivan SD, Smith DH, Weiss KB. The economic burden of asthma in US children: estimates from the National Medical Expenditure Survey. $J$ Allergy Clin Immunol 1999; 104: 957-963.

13. Ungar WJ, Coyte PC and The Pharmacy Medication Monitoring Program Advisory Board. Prospective study of the patient-level cost of asthma care in children. Pediatr Pulmonol 2001; 32: 101-108.

14. Stevens CA, Wesseldine LJ, Couriel JM, Dyer AJ, Osman LM, Silverman M. Parental education and guided self management of asthma and wheezing in the pre-school child: a randomised controlled trial. Thorax 2002; 57: 39-44.

15. Kuehni CE, Davis A, Brooke AM, Silverman M. Are all wheezing disorders in very young (preschool) children increasing in prevalence? Lancet 2001; 357: 1821-1825.

16. Automobile Association. The insider's guide to driving a car: running costs - complete tables - petrol. www.theaa.co.uk/ motoringandtravel/motorcosts/motmot001.asp (no longer exists; similar page: www.theaa.com/allaboutcars/advice/ advice-_rcosts_petrol_table.jsp). Date updated: 2003. Date accessed 9 July 2000.

17. Office for National Statistics. Area and Population: by Local Authority, 1998: Regional Trends 35. London, Stationery Office, 2000.

18. Drummond MF, Jefferson TO. Guidelines for authors and peer reviewers of economics submissions to the BMJ. BMJ 1996; 313: 275-283.

19. Brouwer WB, Koopmanschap MA, Rutten FF. Patient and informal caregiver time in cost-effectiveness analysis: a response to the recommendations of the Washington panel. Int J Technol Assess Health Care 1998; 14: 505-513.

20. Posnett $\mathbf{J}$, Jan $\mathbf{S}$. Indirect cost in economic evaluation: the opportunity cost of unpaid inputs. Health Econ 1996; 5: 13-23.

21. Netten A, Dennett J, Knight J. Unit costs of health and social care. Canterbury, Personal and Social Services Research Unit, University of Kent, 1999.

22. Street A, Dawson D. Costing hospital activity: the experience with healthcare resource groups in England. Eur $J$ Health Econ 2002; 1: 3-9.

23. British Medical Association, Royal Pharmaceutical Society of Great Britain. British National Formulary. No. 39 London, British Medical Association, Royal Pharmaceutical Society of Great Britain, 2000.

24. Department of Health. The Health Survey for England 1997. The Health of Young People '95-97. London, Stationery Office, 1998.

25. South Asian Development Partnership 2001-2002. South Asian Development Partnership. www.southasian.org.uk/ research_popreport_overview.html Date updated: 20012002. Date accessed: 12 August 2002.

26. Department of Health. The Government's Expenditure Plans 1998-1999. London, the Stationery Office, 1998.

27. British Thoracic Society, National Asthma Campaign, Royal College of Physicians of London et al. British guidelines on asthma management: 1995 review and position statement. Thorax 1997; 52: Suppl. 1, S16.

28. Kaur B, Anderson HR, Austin J, et al. Prevalence of asthma symptoms, diagnosis and treatment in 12-14 year old children across Great Britain (International Study of Asthma and Allergies in Childhood, ISAAC UK). BMJ 1998; 316: 118-124. 